\title{
HIDRASI METILISOEUGENOL DENGAN METODE : OKSIMERKURASI-DEMERKURASI
}

\author{
Ngadiwiyana \\ Laboratorium Kimia Organik FMIPA Universitas Diponegoro
}

\section{ABSTRAK}

Telah dilakukan hidrasi metilisoeugenol dengan metode oksimerkurasi-demerkurasi. Metilisoeugenol merupakan hasil isomerisasi metileugenol.

Reaksi oksimerkurasi-demerkurasi dilakukan pada suhu $25^{\circ} \mathrm{C}$. Pada tahap oksimerkurasi digunakan campuran merkuri asetat dengan pelarut $\mathrm{THF}+\mathrm{H}_{2} \mathrm{O}$ dengan perbandingan volume (1:1), sedangkan pada tahap demerkurasi digunakan pereduksi $\mathrm{NaBH}_{4}$ dalam $\mathrm{NaOH}$. Hasil reaksi berupa cairan berwarna putih. Kemurnian hasil ditentukan dengan kromatografi gas, dihasilkan senyawa 1-(3,4-dimetoksifenil)-1-propanol dengan kemurnian 19,20\%. Analisis struktur dilakukan dengan spektrofotometer IR dan kromatografi gas-spektrometer massa.

Kata Kunci : Metilisoegenol, metode oksimerkurasi-demerkurasi, metileugenol, GC, IR, GC-MS.

\section{HIDRATION OF METHYLISOEUGENOL USING: OXIMERCURASITION DEMERCURATION METHOD}

\begin{abstract}
Hydration with oxymercuration-demercuration method to methylisoeugenol have been done. Oxymercuratuion-demercuration reaction was done in $25^{\circ} \mathrm{C}$. Oxymercuration phase used solution of mercury acetate in THF (tetra hydro furan) and $\mathrm{H}_{2} \mathrm{O}(1: 1)$ solvent. Demercuration phase used solution $\mathrm{NaBH}_{4}$ in $\mathrm{NaOH}$ as reducting agent. Product of the reaction was white liquid of 1-(3,4-dimetoxyfenil)-propanol. Measuring by gas chromatography showed that purity of the product is $19.20 \%$. Structure analysis was done by IR spectrophotometer and gas chromatography-mass spectrometer.
\end{abstract}

Keywords : Methylioeugenol, methyleugenol, oxymercuration-demercuration method, GC, IR, GC-MS

\section{PENDAHULUAN}

Indonesia merupakan salah satu negara penghasil beberapa jenis minyak atsiri dan salah satu diantaranya adalah minyak cengkeh. Di dalam negeri pemanfaatan minyak cengkeh masih sangat terbatas. Hanya sebagian kecil minyak yang diproses lebih lanjut menjadi bahan setengah jadi atau menjadi hasil akhir, selebihnya diekspor dalam bentuk minyak mentah (Anwar, 1994).

Minyak cengkeh mengandung dua komponen utama, yaitu eugenol (80-90\%) dan karyofilena (10-20\%). Melihat struktur eugenol yang mengandung beberapa gugus fungsional, yaitu gugus alil, fenol dan eter, maka dimungkinkan untuk merubahnya menjadi senyawa-senyawa turunannya yang lebih berdaya guna. Beberapa turunan eugenol seperti vanilin, metileugenol dan metilisoeugenol banyak digunakan secara lebih luas dalam industri dan tujuan penelitian.

Alkohol dapat disintesis dari berbagai macam cara, salah satu diantaranya ada- 
lah hidrasi suatu alkena. Hidrasi alkena dapat dapat dilakukan dengan menggunakan katalis asam sulfat pekat atau menggunakan merkuri asetat yang dikenal dengan reaksi oksimerkurasi-demerkurasi (metode OM-DM). Dengan metode OM-DM ini akan didapatkan alkohol sampai $90 \%$ dan mempunyai rendemen yang lebih baik daripada hidrasi dengan $\mathrm{H}_{2} \mathrm{SO}_{4}$ (Fessenden, 1986). Persaman reaksi oksimerkurasi-demerkurasi dapat dituliskan sebagai berikut :
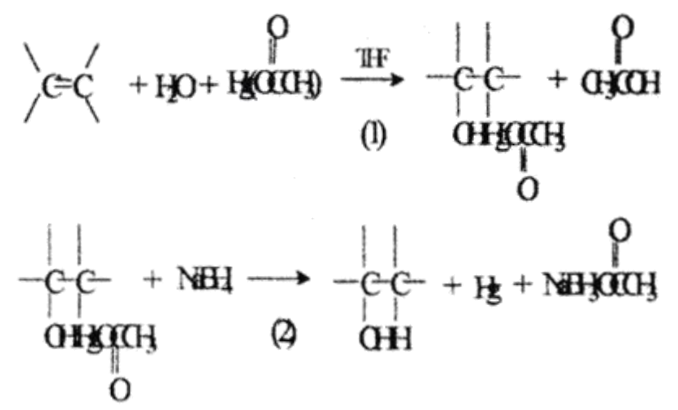

Brown (1970) menyatakan bahwa pada tahap oksimerkurasi akan terjadi tahaptahap sebagai berikut:

Merkuri asetat yang dilarutkan dalam air akan memberikan larutan jernih, dan setelah ditambahkan THF akan timbul endapan kuning. Pada penambahan olefin, endapan atau suspensi yang berwarna kuning akan hilang dan menjadi jernih sehingga akhimya akan didapatkan larutan tidak berwarna, yang dapat terjadi dalam beberapa menit atau beberapa detik tergantung pada olefinnya. Pada saat laru$\tan$ jernih menunjukkan olefin telah teroksimerkurasi, sehingga basa segera ditambahkan untuk menghentikan oksimerkurasi lebih lanjut. Dari keterangan ini maka penambahan basa harus tepat pada saat oksimerkurasi benar-benar telah selesai supaya alkohol yang didapatkan maksimal.

Muslie (1986) telah melakukan reaksi OM-DM terhadap metileugenol dan diperoleh hasil 1-(3,4-dimetoksifenil)-2propanal sebesar 90,1\%. Astuti (1994) juga telah melakukan reaksi OM-DM terhadap metileugenol dan hasil yang diperoleh 98,54\%, Budimarwanti (1997) melakukan hal yang sama dengan hasil $90,31 \%$.

Berdasarkan uraian di atas dan berkaitan dengan tujuan penelitian, maka akan dilakukan adisi $\mathrm{HCl}$ terhadap metilisoeugenol dan hidrasi metilisoeugenol dengan metode OM-DM.

\section{METODE PENELITIAN}

Penelitian pendahuluan meliputi pemurnian eugenol melalui redestilasi pengurangan tekanan. Hasil yang didapat digunakan sebagai bahan dasar untuk reaksi selanjutnya.

\section{Sintesis Metil Eugenol}

$\mathrm{Ke}$ dalam labu leher tiga kapasitas $500 \mathrm{ml}$ yang telah dilengkapi dengan corong penetes, pendingin bola, termometer dan pengaduk magnet dimasukkan $61,16 \mathrm{gr}$ $(0,37 \mathrm{~mol})$ eugenol. Kemudian ditambahkan $18 \mathrm{gr}(0,45 \mathrm{~mol}) \mathrm{NaOH}$ dalam $200 \mathrm{ml}$ air dan campuran diaduk. Ke dalam corong penetes dimasukkan $42,7 \mathrm{~mL}(0,45$ mol) dimetilsulfat, kemudian dimetilsulfat dimasukkan ke dalam labu leher tiga tetes demi tetes selama 1 jam, sementara itu pengadukan dilakukan terus. Campuran direfluks selama 2 jam untuk me- 
nyempurnakan reaksi. Setelah itu dibiarkan dingin, dan campuran diencerkan dalam $100 \mathrm{~mL}$ air, akan terbentuk dua lapisan dan dipisahkan. Lapisan atas $\left(A_{1}\right)$ adalah lapisan organik yang mengandung metileugenol. Lapisan bawah $\left(\mathrm{B}_{1}\right)$ diekstrak dengan petroleum eter $3 \mathrm{kali} 50 \mathrm{~mL}$ untuk mengambil sisa metileugenol. Lapisan atas $\left(A_{1}\right)$ digabung dengan dan diekstrak 2 kali $25 \mathrm{~mL} \mathrm{NaOH} 10 \%$ untuk mengambil eugenol yang tidak bereaksi. Lapisan petroleum eter dicuci dengan akuades sampai netral dan dikeringkan dengan $\mathrm{Na}_{2} \mathrm{SO}_{4}$ anhidrous, kemudian disaring. Petroleum eter dievaporasi dan residu didestilasi dengan pengurangan tekanan.

\section{Isomerisasi Metileugenol}

Dimasukkan $115 \mathrm{~mL}(90,85$ gram) etanol ke dalam labu leher tiga kapasitas $500 \mathrm{ml}$ yang telah dilengkapi dengan termometer, pengaduk magnet, pendingin bola dan tabung silika gel biru. Ke dalam labu leher tiga tersebut ditambahkan 2,3 gram logam natrium sedikit demi sedikit, setelah dingin ditambahkan $150 \mathrm{ml}$ DMSO dan 82 gram metileugenol, kemudian direfluks pada suhu uap $76^{\circ} \mathrm{C}$ selama 9jam. Hasil refluks yang telah dingin ditambah $175 \mathrm{~mL}$ akuades yang telah didinginkan lalu diekstraksi dengan $50 \mathrm{~mL}$ eter sebanyak 2 kali. Lapisan eter dikeringkan dengan $\mathrm{Na}_{2} \mathrm{SO}_{4}$ anhidrous, setelah didekantir kelebihan eter diuapkan dengan evaporator Buchi. Pemurnian dilakukan dengan destilasi fraksinasi dengan pengurangan tekanan. Selanjutnya destilat yang diperoleh ditentukan indeks biasnya dengan refraktometer. Kemurnian diten- tukan dengan kromatografi gas, sedangkan strukturnya ditentukan dengan spektrometer 'H-NMR dan spektroskopi IR.

\section{Reaksi Oksimerkurasi-Demerkurasi} Metilisoeugenol

Ke dalam labu leher tiga kapasitas $100 \mathrm{~mL}$ yang dilengkapi termometer, corong penetes dan pengaduk magnet, dimasukkan 3,19 gram (10 mmol) merkuri (II) asetat, $10 \mathrm{~mL}$ akuades dan diaduk. Setelah merkuri (II) asetat larut ditambahkan $10 \mathrm{~mL}$ tetrahidrofuran, larutan berubah warna menjadi kuning. Kemudian 1,78 gram (10 mmol) metilisoeugenol dimasukkan tetes demi tetes dan suhu $25^{\circ} \mathrm{C}$ (suhu dijaga $25^{\circ} \mathrm{C}$ sampai semua proses selesai). Warna kuning larutan hilang. Dicatat waktu hilangnya warna kuning sejak penambahan metilisoeugenol. Pengadukan dilanjutkan sampai 15 menit lalu ditambahkan $10 \mathrm{~mL}$ larutan $\mathrm{NaOH}$ $3 \mathrm{M}$ diikuti $10 \mathrm{~mL}$ larutan $\mathrm{NaBH}_{4} 0,5 \mathrm{M}$ dalam $\mathrm{NaOH} 3 \mathrm{M}$ secara tetes demi tetes. Reaksi reduksi ini dibiarkan selama 10 menit. Merkuri dibiarkan mengendap dan kemudian ditambahkan larutan $\mathrm{NaCl}$ untuk menjenuhkan lapisan air. Maka terbentuk dua lapisan, lapisan atas dipisahkan dan dikeringkan dengan $\mathrm{Na}_{2} \mathrm{SO}_{4}$ anhidrous. Tetrahidrofuran diuapkan dengan evaporator Buchi. Hasilnya dianalisis dengan kromatografi gas, spektrofotometer infra merah, spektrometer ${ }^{1} \mathrm{HNMR}$ dan kromatogafi gas-spektometer massa.

\section{HASIL DAN PEMBAHASAN}

\section{Redestilasi eugenol}

Eugenol perdagangan berbentuk cair berwarna coklat kehitaman. Setelah dilaku- 
kan redestilasi dengan pengurangan tekanan diperoleh hasil berupa cairan jernih.

\begin{tabular}{|c|c|c|c|c|}
\hline A & $\begin{array}{c}\text { B } \\
\left({ }^{\circ} \mathrm{C}\right)\end{array}$ & $\begin{array}{c}\text { C } \\
(\mathbf{m m H g})\end{array}$ & $\mathbf{D}(\mathrm{g})$ & $\begin{array}{c}\mathbf{E} \\
\star(\%)\end{array}$ \\
\hline I & 32 & 5 & - & - \\
\hline II & 116 & 4 & 119,78 & 98,94 \\
\hline III & 118 & 4 & 334,0 & 100 \\
\hline
\end{tabular}

A: Fraksi, B: Suhu, C: Tekanan D: Berat E : Kemurnian

*=perhitungan \% relatif puncak kromatogram (hanya untuk informasi)

- = tidak dihitung

Untuk selanjutnya fraksi III digunakan sebagai bahan dasar untuk reaksi selanjutnya.

\section{Metilasi Eugenol}

Pada metilasi eugenol setelah destilasi fraksinasi dengan pengurangan tekanan, diperoleh tiga fraksi, yaitu

\begin{tabular}{|c|c|c|c|c|}
\hline $\mathbf{A}$ & $\begin{array}{c}\mathbf{B} \\
\left({ }^{\circ} \mathbf{C}\right)\end{array}$ & $\begin{array}{c}\mathbf{C} \\
(\mathbf{m m H g})\end{array}$ & $\mathbf{D}(\mathbf{g})$ & $\begin{array}{c}\mathbf{E} \\
\left.{ }^{*} \mathbf{\%}\right)\end{array}$ \\
\hline I & 110 & 2 & 4,976 & - \\
\hline II & 111 & 2 & 10,25 & 99,49 \\
\hline III & 112 & 2 & 38,18 & 100 \\
\hline
\end{tabular}

A: Fraksi, B: Suhu, C: Tekanan D: Berat E: Kemurnian

*=perhitungan \% relatif puncak kromatogram (hanya untuk informasi)

- = tidak dihitung

Dari hasil tersebut kemurnian yang paling tinggi diperoleh pada fraksi III, sehingga fraksi III digunakan untuk reaksi selanjutnya. Penentuan struktur fraksi III dilakukan dengan spektrofotometer infra merah, spektroskopi resonansi magnetik inti dan kromatografi gas-MS.
Hasil analisis spektrum inframerah menunjukkan adanya gugus fungsional sebagai berikut :

Adanya pita serapan antara $3100 \mathrm{~cm}^{-1}$ sampai dengan $3000 \mathrm{~cm}^{-1}$ merupakan rentangan $=\mathrm{C}-\mathrm{H}\left(\mathrm{sp}^{2}\right)$. Pita serapan pada $1589,2 \mathrm{~cm}^{-1}$ dan $1517,9 \mathrm{~cm}^{-1}$ menurjukkan bahwa ikatan rangkap tersebut berasal dari inti aromatis. Hal ini didukung oleh adanya serapan pada daerah di bawah $900 \mathrm{~cm}^{-1}$ yang menunjukkan adanya gugus substituen aromatis. Pita serapan pada daerah $1636,4 \mathrm{~cm}^{-1}$ yang diperkuat serapan pada $995,2 \mathrm{~cm}^{-1}$ menunjukkan vibrasi ikatan- $\mathrm{CH}=\mathrm{CH}_{2}$. Adanya ikatan $\mathrm{C}-\mathrm{H}\left(\mathrm{sp}^{3}\right)$ ditunjukkan oleh serapan pada daerah $3000-2800 \mathrm{~cm}^{-1}$, serapan tersebut diperkuat oleh pita serapan pada daerah $1417,6 \mathrm{~cm}^{-1}$ yang menunjukkan adanya gugus metilen $\left(-\mathrm{CH}_{2}\right)$. Spektrum inframerah juga menunjukkan adanya gugus eter (ikatan C-O-C) dengan munculnya pita serapan pada daerah $1300-1200 \mathrm{~cm}^{-1}$ Hasil analisis spektrum ${ }^{1} \mathrm{H}$-NMR dengan pelarut $\mathrm{CCl}_{4}$ menunjukkan $\delta=6,8 \mathrm{ppm}$ (singlet, $3 \mathrm{H}$ ) untuk 3 atom $\mathrm{H}$ cincin aromatis ; $\delta=5,65-6,3$ ppm (multiplet, 1H) untuk $-\mathrm{CH}=; \delta=4,9-5,2 \mathrm{ppm}$ (doublet, $2 \mathrm{H}$ ) untuk $=\mathrm{CH}_{2} ; \delta=3,85 \mathrm{ppm}$ (singlet, $6 \mathrm{H}$ ) untuk 2 gugus $-\mathrm{OCH}_{3}$ dan $\delta$ $=3,3$ ppm (doublet, $2 \mathrm{H}$ ) untuk $-\mathrm{CH}_{2}$ -

\section{Isomerisasi Metileugenol}

Hasil reaksi isomerisasi metileugenol yang masih kotor, dimurnikan melalui destilasi dengan pengurangan tekanan diperoleh hasil sebagai berikut : 


\begin{tabular}{|c|c|c|c|}
\hline Fraksi & $\begin{array}{c}\text { Suhu } \\
\left.\mathbf{C}^{\mathbf{C}} \mathbf{C}\right)\end{array}$ & $\begin{array}{c}\text { Tekanan } \\
(\mathbf{m m H g})\end{array}$ & $\begin{array}{c}\text { Berat } \\
(\mathbf{g r a m})\end{array}$ \\
\hline I & 55 & 3 & 6,33 \\
\hline II & $109-110$ & 3 & 52,32 \\
\hline
\end{tabular}

Fraksi II hasil destilasi tesebut dianalisis dengan kromatografi gas dan menunjukkan 2 puncak dominan. Puncak pada Rt 9,633 menit dengan kelimpahan $16,5668 \%$ menunjukkan senyawa Z-metilisoeugenol dan puncak pada Rt 10,328 menit dengan kelimpahan $83,4332 \%$ menunjukkan senyawa $E$-metilisoeugenol.

Penentuan struktur fraksi II dilakukan dengan spektrofotometer inframerah, spektrometer resonansi magnetik inti dan kromatografi gas-spektrometer massa.

Hasil analisis spektrum inframerah menunjukkan bahwa proses isomerisasi metileugenol menghasilkan metilisoeugenol. Hal ini dapat dilihat dengan hilangnya serapan khas $-\mathrm{CH}=\mathrm{CH}_{2}$ pada daerah $995,2 \mathrm{~cm}^{-1}$, serta munculnya serapan yang karakteristik untuk bentuk isomer Z- dan E-metilisoeugenol, yaitu pada daerah $962,4 \mathrm{~cm}^{-1}$ dan $736,8 \mathrm{~cm}^{-1}$ masingmasing untuk senyawa $Z$ - dan E-metilisoeugenol. Serapan ini diakibatkan oleh vibrasi $=\mathrm{CH}$ lengkung keluar bidang. Persen transmitansi serapan $962,4 \mathrm{~cm}^{-1}$ yang lebih rendah daripada $736,8 \mathrm{~cm}^{-1}$ menunjukkan bahwa isomer $\mathrm{E}$ - lebih dominan daripada isomer Z-metilisoeugenol.

Dengan menggunakan ${ }^{1} \mathrm{H}-\mathrm{NMR}$, dapat ditunjukkan terbentuknya metilisoeugenol dengan munculnya puncak doublet pada $\delta=1,85 \mathrm{ppm}$ oleh serapan $3 \mathrm{H}$ dari $-\mathrm{CH}_{3}$ sebagai pengganti serapan $=\mathrm{CH}_{2}$ pada $\delta=4,9-5,2$ ppm dari senyawa me- tileugenol. Spektrum ${ }^{1}$ H-NMR metilisoeugenol juga menunjukkan hilangnya puncak pada $\delta=3,3 \mathrm{ppm}$ yang merupakan serapan $\mathrm{H}$ pada $-\mathrm{CH}_{2}$ - dari senyawa metileugenol.

Spektrum massa metilisoeugenol hampir sama dengan metileugenol, namun ada perbedaan utama yaitu pecahan dengan m/e 151 yang hanya terdapat pada metileugenol. Pecahan ini dihasilkan oleh lepasnya radikal $-\mathrm{CH}=\mathrm{CH}_{2}$.

\section{Hidrasi Metilisoeugenol dengan Meto- de OM-DM}

Reaksi oksimerkurasi-demerkurasi metilisoeugenol adalah salah satu cara untuk membuat alkohol dari senyawa yang mempunyai ikatan rangkap dua. Pada reaksi ini merkuri asetat dilarutkan dalam pelarut THF : $\mathrm{H}_{2} \mathrm{O}$ dengan perbandingan (1:1). Larutan ini berwarna kuning. Pada penambahan metilisoeugenol larutan berangsur-angsur menjadi jernih, dan tahap ini disebut tahap oksimerkurasi dan kemudian dilanjutkan dengan tahap demerkurasi dengan penambahan $\mathrm{NaBH}_{4}$ dalam $\mathrm{NaOH}$.

Alkohol yang dihasilkan adalah senyawa 1-(3,4-dimetoksifenil)-1-propanol.

Senyawa ini mempunyai sifat dan kenampakan berupa cairan kental berwarna putih dan setelah didiamkan semalam terjadi endapan putih. Hasil analisis dengan kromatografi diperoleh kemumian alkohol sebesar $19,20 \%$. Hasil analisis spektrum inframerah, bila dibandingkan dengan spektrum inframerah metilisoeugenol terdapat perbedaan yang jelas yaitu pada spektrum inframerah hasil reaksi 
OM-DM terdapat serapan melebar pada daerah 3600-3200 $\mathrm{cm}^{-1}$ yang menunjukkan adanya ikatan hidrogen dari gugus hidroksi.

Berdasarkan analisis spektrum infra merah, spektrum ${ }^{1} \mathrm{H}-\mathrm{NMR}$ dan spektrum massa yang mempunyai ion molekuler dengan $\mathrm{m} / \mathrm{z}=196$ dengan pola-pola fragmentasi yang ada, maka hasil reaksi OM-DM metilisoeugenol mempunyai struktur yang dapat dituliskan sebagai berikut :

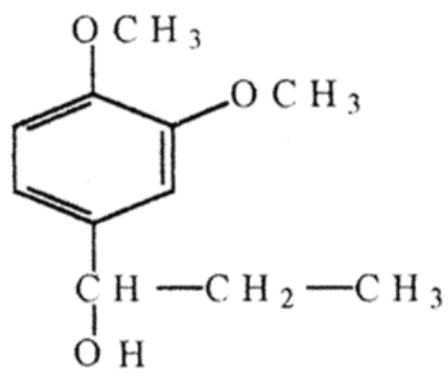

\section{KESIMPULAN}

Berdasarkan hasil penelitian dan pembahasan dapat ditarik kesimpulan sebagai berikut :

Senyawal -(3,4-dimetoksi)-1-propanol dapat disintesis dengan reaksi oksimerkurasi-demerkurasi meilisoeugenol.

\section{DAFTAR PUSTAKA}

1. Anwar, C., 1994, Disertasi : the Conversion of Eugenol into More Valuable Substances, Faculty of Mathematics and Natural Sciences in Gadjah Mada University, Yogyakarta

2. Astuti, D., 1994, Reaksi OksimerkurasiDemerkurasi Metileugenol dan Oksidasi Hasilnya, Skripsi, FMIPA-UGM, Yogyakarta

3. Brown, H. C., 1970, SolvomercurationDemercuration, J. Org. Chem., 35, no. $6,1844-1850$

4. Budimarwanti, 1997, Oksidasi Senyawa 1-(3,4-Dimetoksifenil)-1-Propanol dengan PCC, PDC dan Ahminium Isopropoksida, Tesis, FMIPA-UGM, Yogya.

5. Fessenden, R. J., 1986, Organic Chemistry, Pudjaatmoko, A. H., 1992, Kimia Organik, Jilid I, Edisi Ketiga, Erlangga, Jakarta .

6. Muslie, M., 1986, Reaksi Isomerisasi dan Hidrasi Metileugenol, Skripsi, FMIPA-UGM, Yogyakarta. 